\title{
ARE NON-THERMAL, NON-TUMESCENT TECHNIQUES MORE RECOMMENDED? ENDOVENOUS TREATMENT OF SAPHENOUS VEINS REFLUX - METHODS AND RESULTS OVERVIEW AND DISCUSSION
}

\author{
Adam Zieliński, Paweł Świercz \\ DoktorA Medical Centre, Warszawa, Poland
}

\begin{abstract}
Chronic venous disease is one of the biggest health problems of today's word. The consequences of the progression of venous disorders can lead to severe acute complications like superficial venous thrombosis, deep vein thrombosis, and pulmonary embolism, as well as chronic venous ulcers. The costs of the treatment of these conditions are still growing.

The development of minimally invasive techniques has led to huge progress in the treatment of chronic venous disease. There are many modalities in the phlebological armamentarium, which can be chosen to eliminate axial reflux that is responsible for the progression of disease in the majority of cases. Various groups of techniques can be used: thermal and tumescent procedures, non-thermal tumescent options, or non-thermal non-tumescent treatment. In recent years special interest has been directed towards non-thermal, non-tumescent modalities, following suggestions that these procedures would create the same effects as thermal-tumescent ones, but are less invasive and give the patient a better outcome and quality of life. The review of recently published studies did not confirm this theory in general; however, some superiority of these options is present. Thus, further investigations and trials on this issue are highly recommended. Currently there is not enough strong evidence to promote non-thermal, non-tumescent techniques over other endovenous modalities.
\end{abstract}

Key words: chronic venous disease, endovenous treatment, clinical outcome.
REVIEW PAPER

Phlebological Review 2018; 26, 1: 4-9

DOl: https://doi.org/10.5114/pr.2018.76383

Submitted: 11.04 .2018

Accepted: 4.05 .2018

Address for correspondence

Adam Zieliński

DoktorA Medical Centre

57B Trakt Brzeski St.

05-077 Warszawa, Poland

e-mail: adam.zielinski@doktora.pl

\section{INTRODUCTION}

Chronic venous disease manifests in clinical symptoms like pain, feeling of heaviness of legs, cramps, and itching. These complaints are often related to incompetency of the axial veins of the superficial system like the great saphenous vein (GSV), small saphenous vein (SSV), or anterior accessory saphenous vein (AASV). Elimination of the reflux in these vessels is not only essential for the improvement of symptoms but also can prevent acute complications of venous disease like superficial venous thrombosis, deep vein thrombosis, and pulmonary embolism. Elimination of varicosities also diminishes the possibility of acute bleeding in the case of varicose vein injury.

Because conservative treatment with medical compression stockings and venoactive drugs is not recommended as the only possibility and is not popular, especially amongst young and active patients, interventional options have gained a lot of popularity in developed health care systems. In the last decade, the highest interest of patients and phlebologists has been directed to minimally invasive, endovenous techniques. The major advantages of them are the possibility to perform the pro- cedure without general or spinal anaesthesia and immediate recovery and return to work time.

Endovenous modalities of the treatment of axial reflux in chronic venous disease (CVD) have been present in phlebological armamentarium for many years. They include thermal and tumescent (TT) procedures like laser ablation (EVLA), radiofrequency (RF), or steam (SVS), and non-thermal tumescent (NTT) options like long-catheter foam sclerotherapy or non-thermal non-tumescent (NTNT) treatment, which include mechano-chemical ablation (MOCA) and glue (CA).

Some of the thermal and tumescent procedures were introduced to phlebology over 15 years ago, like RF and laser (first results in 1999) [1,2]. They have strong recommendations for use, and well-known complications and limitations. So now the debate is not about whether they should be used, or even what the indications are for them, but rather how to avoid the side effects connected with the treatment and eliminate even mild and insignificant complications. Since international guidelines clearly indicate that laser and radiofrequency are the methods of choice in axial reflux elimination $[3,4]$, these procedures have been 
used as a comparator to surgical treatment [5-7]. Following the results of such trials, newer minimally invasive modalities of eliminating of venous reflux have been assessed and compared to EVLA or RF. Nevertheless, the latest of these are still being developed and changed, giving new perspectives for usage and revealing better results.

\section{METHODS OVERVIEW}

\section{Endovenous thermal ablation (EVTA)}

Endovenous laser ablation (EVLA) seems to be the most widespread modality of EVTA [8]. The first studies describing the results of EVLA reported the use of a haemoglobin targeting wavelength of $810 \mathrm{~nm}$, subsequently followed by longer wavelengths - 940, 980, and $1064 \mathrm{~nm}$. A trigger to look for other options was the conception of using water as a chromophore for laser light, and this thought led to development of generators producing higher wavelengths that target the vein wall instead of blood (1320, 1470, 1500, 1920, or $2100 \mathrm{~nm}$ ). Although the results of studies comparing efficacy and safety of laser procedures performed using two different groups of generators are not fully consistent, there are some papers advocating application of water-absorbing waves to reduce pain and bruising [9-12].

Another important factor influencing the results of EVLA is fibre type. The possibility of vein wall injury and subsequent perforation caused by direct contact of the fibre with the endothelium has led to the development of many types of fibre tips, which are more commonly used now instead of a bare tip fibre: radial or bi-radial, spherical, covered, or tulip tipped catheters [13-15]. Due to the spherical or radial shape of the laser beam or by covering the energy-emitting part of the fibre, the delivered energy is diffused and energy density is lowered, so the possibility of perforation of the wall is essentially eliminated. Upon the results of recent papers, it seems that the EVLA procedures connecting longer wavelength generators with new fibres are safer and more efficient [16-18].

Radiofrequency ablation (RF) is a method similar to EVLA, which was introduced to the endovenous treatment in 1999 as the Closure Plus (VNUS) system being the first FDA-approved method of thermal ablation [19]. As the low pullback speed made the procedure duration too long, in 2007 it was replaced by the RF segmental system - Closure Fast with a $7-\mathrm{cm}$ therapeutic distal tip. To treat shorter segments of veins, a $3-\mathrm{cm}$ heating probe was introduced in 2012. The results of the RF treatment are similar to those using laser $[20,21]$. The other conception using radiofrequency is bipolar thermotherapy utilising blood and vein wall as a conductor, which is heated (RFITT).

Steam ablation (SVS) is the most recently introduced method of EVTA. Currently there are two systems available - Steam Vein Sclerosis and VBox System. The meth- od allows truncal reflux treatment and can be used to ablate tributaries and malformations. Although there are very few publications on steam ablation, and the worldwide experience is limited, preliminary results are promising, showing non-inferiority to other thermal procedures [22-24].

\section{Mechano-chemical ablation (MOCA)}

Mechano-chemical ablation is one of NTNT methods of abolishing the reflux in saphenous veins. The first used MOCA device was ClariVein . Apart from minimal local anaesthesia at the puncture site, the system does not require any additional analgesia. Although the results of MOCA procedures are promising and comparable to TT ones, it should be remembered that only one saphenous vein can be closed within 24 hours because of the dose limitation of the sclerosing agent [25].

Another MOCA modality is the Flebogrif ${ }^{\mathrm{TM}}$ system, which utilises specific expendable hooks to scratch the intima prior to sclerosant injection. Scarification should result in better vein constriction and direct contact between the vessel wall and injected foam. Although only preliminary results have been published, they are promising [26].

\section{Glue ablation (cyanoacrylate ablation - CA)}

The most recent development of NTNT saphenous vein ablation is glue. Primarily cyanoacrylate glue (Medtronic VenaSeal ${ }^{\mathrm{TM}}$ ) was introduced and researched as a method compared to TT methods. Several studies revealed good results after up to three years of follow-up [27, 28]. Recently, other medical adhesives have also been introduced to abolish venous reflux, like Biolas VariClose ${ }^{\circledast}$ or Invamed VenaBlock $^{\oplus}$ treatment systems. There are some technical details that differ between the systems, like glue viscosity (which is lower for VariClose ${ }^{\circledR}$ ), the patterns of application (interrupted or continuous), the catheter type, or tip positioning at the saphenofemoral junction. The first results of VariClose ${ }^{\circledast}$ procedures are promising [29], but longer follow-up data are still lacking. In contrast to foam sclerotherapy or MOCA, there is no limitation of dosage while using CA, hence even four saphenous veins can be treated in one session. As opposed to the majority of other ablation methods, post-procedural compression is not essential after intervention.

\section{RESULTS OF THE ENDOVENOUS ABLATION TECHNIQUES - TECHNICAL SUCCESS}

\section{Early results}

Laser and radiofrequency methods have been widely described because they are the oldest and most pop- 
ular modalities of abolishing the saphenous vein reflux. As for 2014, 67 and 47 studies were published showing the results of EVLA and RF, respectively [30]. In a group of trials performed after 2010, which is when modern modalities have been introduced, pooled for follow-up time up to six months, the rate of occlusion of saphenous veins range between $100 \%$ and $93.3 \%$ for laser and between $100 \%$ and $86.4 \%$ for radiofrequency. Also, novel techniques have been assessed. For SVS the early success rate varies from $65 \%$ to $95 \%$, whereas in the most recently published reviews, the pooled anatomic success for MOCA and CA was $94.7 \%$ and $94.8 \%$ at six months, respectively [31]. These data indicate very good shortterm results of all modalities of endovenous ablation. There is also a suggestion, revealed by recent publications, that NTNT methods are more effective compared to TT methods. This conclusion must be revised by further investigations, especially describing longer periods of follow-up and larger cohorts of patients.

\section{Mid-term results}

For TT methods many studies with mid-term follow-up have proven the durability of EVTA. The rate of closure of saphenous veins after such procedures are still higher that $90 \%$ in the majority of trials. The Varico- 2 study showed $96.2 \%$ and $96.6 \%$ of closed trunks after 60 months for RF and EVLA, respectively [32].

It seems undebatable that SVS and NTNT methods are becoming more interesting, so some studies have been conducted to assess their efficacy and to compare them to TT. The LAST trial showed non-inferiority of technical success rate while preforming steam ablation compared to EVLA - $92 \%$ vs. $96 \%$ of closed saphenous veins after one year of observation $(p=0.331)$ [33]. The VeClose Study, which was performed to compare glue ablation (VenaSeal $^{\mathrm{TM}}$ ) with RF modality revealed $94.4 \%$ of closed saphenous veins in a cyanoacrylate group vs. $91.9 \%$ in an RF group after 36 months of follow-up [34]. Another midterm study, the eSCOPE trial, showed that three years after VenaSeal $^{\mathrm{TM}}$ procedure $88.5 \%$ of saphenous veins were free from recanalisation [35], whereas Almeida et al. reported $94.7 \%$ of successfully closed GSV trunks 36 months after cyanoacrylate ablation [36]. For the treatment with n-butyl cyanoacrylate derivative, similar results have been published showing $94.1 \%$ of closed veins after 30 months of follow-up [37]. There are not so many studies analysing mid-term outcomes of MOCA. One of them was performed to assess the ClariVein device to abolish SSV reflux. The closure rate after one year was 94\% [38], and for GSV the clinical success rate was 93\% [39]. Mirrandola reported a success rate of $89 \%$ after 36 months [40], whereas Witte et al. $-87 \%$ [41] while using MOCA to treat incompetent superficial veins.

\section{Long-term results}

The assessment of long-term results of TT methods can be used only for RF and EVLA because they have been the only modalities present in the phlebological armamentarium for more than 10 years. There are some studies showing good rates of closure of saphenous trunks. The ELA-FOS study evaluated the durability of laser treatment after 66 to 110 months (mean 88) of follow-up and showed partial recanalisation in only $3.4 \%$ and total recanalisation in $5.1 \%$ of treated veins [42]. Also, RF procedure results seem to be stable for longer periods after the procedure. Proebstle et al. reported a high occlusion rate of $91.9 \%$ of treated veins after five years of follow-up [43], while the study of the longest observation time after EVTA showed a rate of $88.1 \%$ of technical success 15 years after RF VNUS closure [44].

\section{Foam sclerotherapy}

The oldest modality of endovenous treatment of axial reflux is ultrasound-guided foam sclerotherapy (UGFS). This method has had a well-established place in phlebology although the majority of trials show worse results of UGFS compared to TT or novel NTNT techniques. Occlusion rate at one year ranges between 51 and $75 \%$ [45-48] and is significantly lower at five years, up to $23 \%$ of closed veins in van der Velden et al. RCT [49]. Despite worse technical results, clinical outcomes of foam therapy measured by CIVIQ or EQ-5D do not differ from EVTA, especially at one year, thus making UGFS still an attractive method, particularly considering the cost-effectiveness of the therapy.

\section{RESULTS OF THE ENDOVENOUS ABLATION TECHNIQUES - CLINICAL OUTCOME}

It is essential for the clinician physician to assess the results of the procedures first of all from the patient's perspective. It means that we should compare health-related quality of life after the treatment, not only technical and anatomical findings. Because there are many factors influencing the clinical outcome, reliable assessment is complicated. It is especially difficult for EVTA, because many different devices and modifications of treatment have been used for more than 15 years of the history of endovenous thermal ablation. For example, the bare fibre tip combined with laser generators producing $810 \mathrm{~nm}$ wavelength should not be compared with contemporary implemented equipment, similarly it is not advisable to check VNUS against the Closure Fast system. Hence the NTNT are not so varied, and their results' comparison is more reliable inside each group.

The analysis of patients' quality of life after EVTA reveals improvement compared to open surgery in shortterm, mid-term, and long-term follow-up [7, 45, 50]. In 
short- and mid-term time after the procedure, the rate of clinical complications is also very low for NTNT [51], even the intra- and postprocedural pain seems to be lower for MOCA and CA than for EVTA. Other minor and major complication rates, time to return to work, and normal activity do not differ significantly [36, 52-56].

Simultaneously, clinical outcomes must be evaluated considering the recurrence rates. The precise assessment is then more accurate when longer follow-up periods are taken into account. Thus, only EVTA modalities can be measured because they are unique methods that have been used long enough to be compared to open surgery. The results of mid-term and long-term trials reveal the same recurrence rates of varicosity after EVTA compared to open surgery - high ligation and stripping $(46.6 \%$ and $54.6 \%$, respectively) [57]. According to recent trials the resources of recurrences are better established and it is suspected that same-site recurrence is more often expected after EVTA procedures compared to open surgery, while the relief of venous symptoms, changes of CEAP stages, and quality of life are equally improved $[58,59]$. The most frequently found cause of recurrent disease is neovascularisation and incompetency of thigh perforators after surgery or refluxing groin tributaries for EVTA. That is why some modifications of EVLA technique are proposed, like laser GSV crossectomy, i.e. ablation starting at the saphenofemoral junction $[60,61]$. This method is suspected to be more efficient in preventing reflux augmentation from coming into the groin tributaries, especially to AASV, and forming varicosity. If AASV is visible, but not refluxing at the time of primary procedure, it is estimated that this vessel can be a source of recurrence in $55 \%$ of cases [62]. Thus, a very meticulous postprocedural patient control strategy is mandatory and elimination of detected reflux from the junction required. In cases when reflux is present in AASV at the time of primary procedure, it is proposed that it be eliminated simultaneously by the same technique that is planned for GSV ablation.

\section{CONCLUSIONS}

It is clearly visible that the development of endovenous techniques used in chronic venous disease has created a new perspective in phlebology. The treatment can be easier, faster, and - what is most important for the patient - safer and more effective. As an evident reduction of complications and improvement of quality of life of the patients after the procedures can be reached by all endovenous methods, it is crucial to adjust the proper mode of therapy to the specific patient and type of disease. Each minimally invasive way is valuable unless used by a skilled and qualified specialist. The differences of effectiveness among the modalities are very small and require further investigations and well-designed trials without any commercial bias. It is crucial to wait for long follow-up assessment of the newest techniques to be able to compare them to the older ones. Currently it is not clear that non-tumescent non-thermal modalities should be chosen as a first option in the treatment to eliminate saphenous reflux.

\section{The authors declare no conflict of interest.}

\section{References}

1. Manfrini S, Gasbarro V, Danielsson G, Norgren L, Chandler JG, Lennox AF, Zarka ZA, Nicolaides AN. Endovenous management of saphenous vein reflux. Endovenous Reflux Management Study Group. J Vasc Surg 2000; 32: 330-342.

2. Bone C. Tratamiento endoluminal de las varices con laser de diodo: estudio preliminary. Rev Patol Vasc 1999; 5: 35-46.

3. Gloviczki P, Comerota AJ, Dalsing MC, Eklof BG, Gillespie DL, Gloviczki ML, Lohr JM, McLafferty RB, Meissner MH, Murad MH, Padberg FT, Pappas PJ, Passman MA, Raffetto JD, Vasquez MA, Wakefield TW, Society for Vascular Surgery, American Venous Forum. The care of patients with varicose veins and associated chronic venous diseases: Clinical practice guidelines of the Society for Vascular Surgery and the American Venous Forum. J Vasc Surg 2011; 53 (5 Suppl.): 2S-48S.

4. Wittens C, Davies AH, Bækgaard N, Broholm R, Cavezzi A, Chastanet S, de Wolf M, Eggen C, Giannoukas A, Gohel M, Kakkos S, Lawson J, Noppeney T, Onida S, Pittaluga P, Thomis S, Toonder I, Vuylsteke M, Kolh P, de Borst GJ, Chakfé N, Debus S, Hinchliffe R, Koncar I, Lindholt J, de Ceniga MV, Vermassen F, Verzini F, De Maeseneer MG, Blomgren L, Hartung O, Kalodiki E, Korten E, Lugli M, Naylor R, Nicolini P, Rosales A. Editor's Choice - Management of Chronic Venous Disease: Clinical Practice Guidelines of the European Society for Vascular Surgery (ESVS). Eur J Vasc Endovasc Surg 2015; 49: 678-737.

5. Siribumrungwong B, Noorit P, Wilasrusmee C, Attia J, Thakkinstian A. A systematic review and meta-analysis of randomised controlled trials comparing endovenous ablation and surgical intervention in patients with varicose vein. Eur J Vasc Endovasc Surg 2012; 44: 214-223.

6. Flessenkämper I, Hartmann M, Hartmann K, Stenger D, Roll S. Endovenous laser ablation with and without high ligation compared with high ligation and stripping for treatment of great saphenous varicose veins: Results of a multicentre randomised controlled trial with up to 6 years follow-up. Phlebology 2016; 31: 23-33.

7. Nesbitt C, Bedenis R, Bhattacharya V, Stansby G. Endovenous ablation (radiofrequency and laser) and foam sclerotherapy versus open surgery for great saphenous vein varices. Cochrane Database of Syst Rev 2014; 7: CD005624.

8. van der Velden SK, Pichot O, van den Bos RR, Nijsten TE, De Maeseneer MG. Management Strategies for Patients with Varicose Veins (C2-C6): Results of a Worldwide Survey. Eur J Vasc Endovasc Surg 2015; 49: 213-220.

9. Mendes-Pinto D, Bastianetto P, Cavalcanti Braga Lyra L, Kikuchi R, Kabnick L. Endovenous laser ablation of the great saphenous vein comparing 1920-nm and 1470-nm diode laser. Int Angiol 2016; 35: 599-604.

10. Jibiki M, Miyata T, Futatsugi S, Iso M, Sakanushi Y. Effect of the wide-spread use of endovenous laser ablation on the treatment of varicose veins in Japan: a large-scale, single institute study. Laser Ther 2016; 25: 171-177. 
11. Almeida J, Mackay E, Javier J, Mauriello J, Raines J. Saphenous laser ablation at $1470 \mathrm{~nm}$ targets the vein wall, not blood. Vasc Endovasc Surg 2009; 43: 467-472.

12. Vulsteke M, De Bo TH, Dompe G, Di Crisci D, Abbad CM, Mordon S. Endovenous laser treatment: is there a clinical difference between using a $1500 \mathrm{~nm}$ and a $980 \mathrm{~nm}$ diode laser? A multicenter randomized clinical trial. Int Angiol 2011; 30: 327-234.

13. Schwarz T, von Hodenberg E, Furtwangler C, Rastan A, Zeller T, Neumann FJ. Endovenous laser ablation of varicose veins with the 1470-nm diode laser. J Vasc Surg 2010; 51: 1474-1478.

14. Prince EA, Soares GM, Silva M, Taner A, Ahn S, Dubel GJ, Jay BS. Impact of laser fiber design on outcome of endovenous ablation of lower-extremity varicose veins: results from a single practice. Cardiovasc Intervent Radiol 2011; 34: 536-541.

15. Vuylsteke M, Van Dorpe J, Roelens J, De Bo T, Mordon S, Fourneau I. Intraluminal fibre-tip centring can improve endovenous laser ablation: a histological study. Eur J Vasc Endovasc Surg 2010; 40: 110-116.

16. Yamamoto T, Sakata M. Influence of fibers and wavelengths on the mechanism of action of endovenous laser ablation. J Vasc Surg Venous Lymphat Disord 2014; 2: 61-69.

17. Hirokawa M, Ogawa T, Sugawara H, Shokoku S, Sato S. Comparison of $1470 \mathrm{~nm}$ Laser and Radial 2ring Fiber with $980 \mathrm{~nm}$ Laser and Bare-Tip Fiber in Endovenous Laser Ablation of Saphenous Varicose Veins: A Multicenter, Prospective, Randomized, Non-Blind Study. Ann Vasc Dis 2015; 8: 282-289.

18. Doganci S, Demirkilic U. Comparison of $980 \mathrm{~nm}$ laser and baretip fibre with $1470 \mathrm{~nm}$ laser and radial fibre in the treatment of great saphenous vein varicosities: a prospective randomized clinical trial. Eur J Vasc Endovasc Surg 2010; 40: 254-259.

19. Goldman MP. Closure of the greater saphenous vein with endoluminal radiofrequency thermal heating of the vein wall in combination with ambulatory phlebectomy: preliminary 6-month follow-up. Dermatol Surg 2000; 26: 452-456.

20. He G, Zheng C, Yu MA, Zhang H. Comparison of ultrasoundguided endovenous laser ablation and radiofrequency for the varicose veins treatment: An updated meta-analysis. Int J Surg 2017; 39: 267-275.

21. Davies HO, Popplewell M, Darvall K, Bate G, Bradbury AW. A review of randomised controlled trials comparing ultrasound-guided foam sclerotherapy with endothermal ablation for the treatment of great saphenous varicose veins. Phlebology 2016; 31: 234-240.

22. van den Bos RR, Milleret R, Neumann M, Nijsten T. Proof-of principle study of steam ablation as novel thermal therapy for saphenous varicose veins. J Vasc Surg 2010; 53: 181-186.

23. Milleret R, Huot L, Nicolini P, Creton D, Roux AS, Decullier E, Chapuis FR, Camelot G. Great saphenous vein ablation with steam injection: results of a multicentre study. Eur J Vasc Endovasc Surg 2013; 45: 391-396.

24. Mlosek RK, Woźniak W, Gruszecki L, Stapa RZ. The use of a novel method of endovenous steam ablation in treatment of great saphenous vein insufficiency: own experiences. Phlebology 2014; 29: 58-65.

25. Lane T, Bootun R, Dharmarajah B, Lim CS, Najem M, Renton S, Sritharan K, Davies AH. A multi-centre randomized controlled trial comparing radiofrequency and mechanical occlusion chemically assisted ablation of varicose veins - Final results of the Venefit versus Clarivein for varicose veins trial. Phlebology 2017; 32: 89-98.
26. Zubilewicz T, Terlecki P, Terlecki K, Przywara S, Rybak J, Ilzecki M. Application of endovenous mechanochemical ablation (MOCA) with Flebogrif ${ }^{\text {si }}$ to treat varicose veins of the lower extremities: a single center experience over 3 months of observation. Acta Angiol 2016; 22: 137-142.

27. Marston WA. Invited Commentary. J Vasc Surg Venous Lymphat Disord 2017; 5: 666.

28. Proebstle TM, Alm J, Dimitri S, Rasmussen L, Whiteley M, Lawson J, Cher D, Davies A. The European multicenter cohort study on cyanoacrylate embolization of refluxing great saphenous veins. J Vasc Surg Venous Lymphat Disord 2015; 31: 2-7.

29. Çalık ES, Arslan Ü, Ayaz F, Tort M, Yıldız Z, Aksu V, Onk OA, Limandal HK, Ekingen E, Dağ Ö, Kaygın MA, Erkut B. N-butyl cyanoacrylate in the treatment of venous insufficiency - the effect of embolisation with ablative polymerisation. Vasa 2016; 45: 241-246.

30. van Eekeren RR, Boersma D, de Vries JP, Zeebregts CJ, Reijnen MM. Update of endovenous treatment modalities for insufficient saphenous veins-A review of literature. Semin Vasc Surg 2014; 27: 118-136.

31. Vos CG, Ünlü Ç, Bosma J, van Vlijmen CJ, de Nie AJ, Schreve MA. A systematic review and meta-analysis of two novel techniques of nonthermal endovenous ablation of the great saphenous vein. J Vasc Surg Venous Lymphat Disord 2017; 5: 880-896.

32. Lawson JA, Gauw SA, van Vlijmen CJ, Pronk P, Gaastra MTW, Tangelder MJ, Mooij MC. Prospective comparative cohort study evaluating incompetent great saphenous vein closure using radiofrequency-powered segmental ablation or 1470-nm endovenous laser ablation with radial-tip fibers (Varico 2 study). J Vasc Surg Venous Lymphat Disord 2018; 6: 31-40.

33. van den Bos RR, Malskat WS, De Maeseneer MG, de Roos KP, Groeneweg DA, Kockaert MA, Neumann HA, Nijsten T. Randomized clinical trial of endovenous laser ablation versus steam ablation (LAST trial) for great saphenous varicose veins. $\mathrm{Br}$ J Surg 2014; 101: 1077-1083.

34. Gibson K. 3-year outcomes from the VeClose United States pivotal clinical trial. $39^{\text {th }}$ Charing Cross Symposium, $27^{\text {th }}$ of April 2017, London.

35. Proebstle T. VenaSeal clinical overview: Highlights from FIH, eSCOPE and VeClose clinical studies. Leipzig Interventional Course, $25^{\text {th }}$ of January 2017, Lepizig.

36. Almeida JI, Javier JJ, Mackay EG, Bautista C, Cher DJ, Proebstle TM. Thirty-sixth-month follow-up of first-in-human use of cyanoacrylate adhesive for treatment of saphenous vein incompetence. J Vasc Surg Venous Lymphat Disord 2017; 5: 658-666.

37. Eroglu E, Yasim A, Ari M, Ekerbicer H, Kocarslan A, Kabalci M, Acıpayam M. Mid-term results in the treatment of varicose veins with N-butyl cyanoacrylate. Phlebology 2017; 32: 665669.

38. Boersma D, van Eekeren RR, Werson DA, van der Waal RI, Reijnen MM, de Vries JP. Mechanochemical endovenous ablation of small saphenous vein insufficiency using the ClariVein $\left({ }^{\circ}\right.$ ) device: one-year results of a prospective series. Eur J Vasc Endovasc Surg 2013; 45: 299-303.

39. van Eekeren RR, Boersma D, Holewijn S, Werson DA, de Vries JP, Reijnen MM. Mechanochemical endovenous ablation for the treatment of great saphenous vein insufficiency. J Vasc Surg Venous Lymphat Disord 2014; 2: 282-288.

40. Mirrandola M, Griso A, Migliara B, Cappellari T, Lino M. Mechanochemical ablation of saphenous vein: learning from 4 years 
follow up. $18^{\text {th }}$ Congress of European Venous Forum, $29^{\text {th }}$ of June 2017, Porto.

41. Witte ME, Holewijn S, van Eekeren RR, de Vries JP, Zeebregts CJ, Reijnen MM. Midterm Outcome of Mechanochemical Endovenous Ablation for the Treatment of Great Saphenous Vein Insufficiency. J Endovasc Ther 2017; 24: 149-155.

42. Kontokhanassis D, De Zolt P, Labropoulos N. Endovenous Laser Ablation Follow Up Study (ELA-FOS). A Prospective Trial to Assess Long Term EVLA Results. XVII World Meeting of the International Union of Phlebology, $8-13^{\text {th }}$ of September 2013, Boston.

43. Proebstle TM, Alm J, Gockeritz O, Wenzel C, Noppeney T, Lebard C, Sessa C, Creton D, Pichot O. Five-year results from the prospective European multicentre cohort study on radiofrequency segmental thermal ablation for incompetent great saphenous veins. Brit J Surg 2015; 102: 212-218.

44. Whiteley MS, Shiangoli I, Dos Santos SJ, Dabbs EB, Fernandez-Hart TJ, Holdstock JM. Fifteen Year Results of Radiofrequency Ablation, Using VNUS Closure, for the Abolition of Truncal Venous Reflux in Patients with Varicose Veins. Eur J Vasc Endovasc Surg 2017; 54: 357-362.

45. Rasmussen LH, M, Bjoern L, Vennits B, Blemings A, Eklof B. Randomized clinical trial comparing endovenous laser ablation, radiofrequency ablation, foam sclerotherapy and surgical stripping for great saphenous varicose veins. Br J Surg 2011; 98: 1079-1087.

46. Shadid N, Ceulen R, Nelemans P, Dirksen C, Veraart J, Schurink GW, van Neer P, vd Kley J, de Haan E, Sommer A. Ultrasound-guided foam sclerotherapy versus surgery for the incompetent great saphenous vein: a multicentre randomised controlled non-inferiority trial. Br J Surg 2012; 99: 1062-1070.

47. Chapman-Smith P, Browne A. Prospective five-year study of ultrasound-guided foam sclerotherapy in the treatment of great saphenous vein reflux. Phlebology 2009; 24: 183-188.

48. Thomasset SC, Butt Z, Liptrot S, Fairbrother BJ, Makhdoomi KR. Ultrasound guided foam sclerotherapy: factors associated with outcomes and complications. Eur J Vasc Endovasc Surg 2010; 40: 389-392.

49. van der Velden SK, Biemans AA, De Maeseneer MG, Kockaert MA, Cuypers PW, Hollestein LM, Neumann HA, Nijsten T, van den Bos RR. Five-year results of a randomized clinical trial of conventional surgery, endovenous laser ablation and ultrasound-guided foam sclerotherapy in patients with great saphenous varicose veins. Br J Surg 2015; 102: 1184-1194.

50. Venermo M, Saarinen J, Eskelinen E, Vähäaho S, Saarinen E, Railo M, Uurto I, Salenius J, Albäck A, Finnish Venous Study Collaborators. Randomized clinical trial comparing surgery, endovenous laser ablation and ultrasound-guided foam sclerotherapy for the treatment of great saphenous varicose veins. $\mathrm{Br}$ J Surg 2016; 103: 1438-1444.

51. Elias S, Raines JK. Mechanochemical tumescentless endovenous ablation: final results of the initial clinical trial. Phlebology 2012; 27: 67-72.

52. Bootun R, Lane TR, Dharmarajah B, Lim CS, Najem M, Renton S, Sritharan K, Davies AH. Intra-procedural pain score in a randomised controlled trial comparing mechanochemical ablation to radiofrequency ablation: The Multicentre Venefit ${ }^{\mathrm{nt}}$ versus ClariVein ${ }^{\star}$ for varicose veins trial. Phlebology 2016; 31: 61-65.

53. van Eekeren RR, Boersma D, Konijn V, de Vries JP, Reijnen MM. Postoperative pain and early quality of life after radiofrequency ablation and mechanochemical endovenous ablation of incompetent great saphenous veins. J Vasc Surg 2013; 57: 445-450.
54. Vun SV, Rashid ST, Blest NC, Spark JI. Lower pain and faster treatment with mechanico-chemical endovenous ablation using ClariVein ${ }^{\circ}$. Phlebology 2015; 30: 688-692.

55. Bozkurt AK, Yllmaz MF. A prospective comparison of a new cyanoacrylate glue and laser ablation for the treatment of venous insufficiency. Phlebology 2016; 31 (1 Suppl.): 106-113.

56. Leung C, Carradice D, Mohamed A, Wallace T, Chetter I. The Lama Trial - A Randomized Controlled Trial Comparing Endovenous Laser Ablation Versus Mechanochemical Ablation In The Treatment Of Superficial Venous Incompetence. ESVS $31^{\text {st }}$ Annual Meeting, 20 $0^{\text {th }}$ of September 2017, Lyon.

57. Rasmussen L, Lawaetz M, Bjoern L, Blemings A, Eklof B. Randomized clinical trial comparing endovenous laser ablation and stripping of the great saphenous vein with clinical and duplex outcome after 5 years. J Vasc Surg 2013; 58: 421-426.

58. Rass K, Frings N, Glowacki P, Gräber S, Tilgen W, Vogt T. Same Site Recurrence is More Frequent After Endovenous Laser Ablation Compared with High Ligation and Stripping of the Great Saphenous Vein: 5 year Results of a Randomized Clinical Trial (RELACS Study). Eur J Vasc Endovasc Surg 2015; 50: 648-656.

59. Gauw SA, Lawson JA, van Vlijmen-van Keulen CJ, Pronk P, Gaastra MT, Mooij MC. Five-year follow-up of a randomized, controlled trial comparing saphenofemoral ligation and stripping of the great saphenous vein with endovenous laser ablation (980 nm) using local tumescent anesthesia. J Vasc Surg 2016; 63: 420-428.

60. Maurins U. Phlebological center based on laser technique - lessons learned, practical advices. International Meeting of Aesthetic Phlebology, $3^{\text {rd }}$ of March 2018, Sao Paulo.

61. Dragic P. Edited live case - EVLA of great saphenous vein. International Meeting of Aesthetic Phlebology, $4^{\text {th }}$ of March 2018, Sao Paulo.

62. Proebstle TM, Möhler T. A longitudinal single-center cohort study on the prevalence and risk of accessory saphenous vein reflux after radiofrequency segmental thermal ablation of great saphenous veins. J Vasc Surg Venous Lymphat Disord 2015; 3: 265-269. 